\title{
América Latina y lo clásico. Lo clásico y América Latina
}

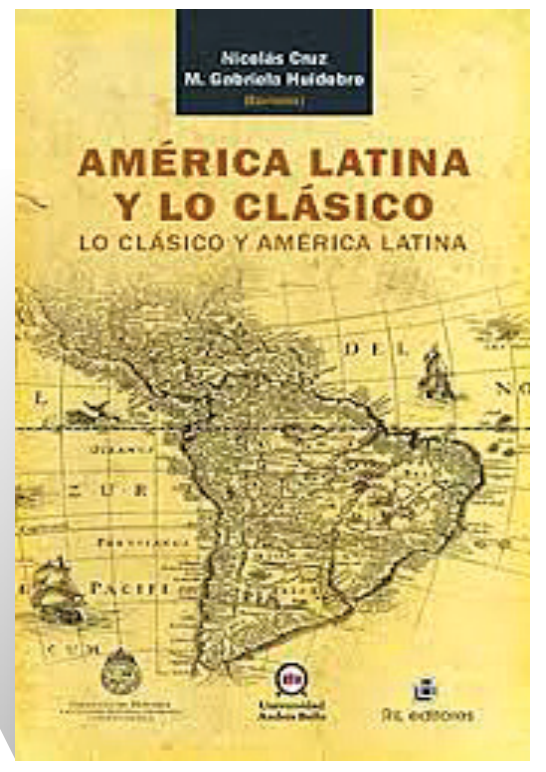

FICHA BIBLIOGRÁFICA

N. Cruz, M.G. Huidobro (editores), América Latina y lo clásico. Lo clásico y América Latina, $1^{\text {a }}$. Edición, Instituto de Historia, Facultad de Historia, Geografía y Ciencia Política, Universidad Andrés Bello, RL eds., Santiago de Chile, 2018, 340 pp. ISBN 978-956-01-0550-9.

\section{Eleonora Dell' Elicine I Universidad de Buenos Aires}

COMO SU TítUlo INDICA, EL PROBLEMA QUE VERTEBRA ESTE Libro es la compleja relación entre la cultura grecorromana y América Latina. Los 15 artículos que lo integran profundizan en aspectos muy variados de la cuestión -recepción textual, impacto en prácticas, modos de comunicar, formas de hacer ciudad, etc. Esta variedad se mueve con comodidad en diferentes escenarios regionales -territorios de los actuales Chile, Brasil, Méjico, Colombia, Argentina, California, etc.--, a lo largo de un arco temporal que se inicia en el siglo XVI y se extiende hasta la segunda mitad del siglo XX.

La introducción a cargo de los editores señala la vocación interdisciplinaria de la propuesta. A lo largo de sus hojas efectivamente desfilan objetos distintos, muchos de ellos tra- 
bajados en su interior en diferentes perspectivas. El caso del artículo de Carolina Domínguez, combinando análisis de las políticas educativas y lingüísticas para dar cuenta de los vaivenes curriculares de las lenguas clásicas en Argentina durante el siglo XIX, o el examen de las tertulias, bibliotecas y periódicos que propone Ricardo Del Molino para Nueva Granada, muestran con bastante exactitud este diálogo disciplinar que los editores han sabido promover en el libro.

La introducción no desgrana ni extensiva ni conceptualmente la complejidad del problema que se plantea. El lector lo percibe desde el índice y con material interesante a lo largo de la obra: la cultura clásica en América latina se hace presente en los más diversos códigos. Principalmente los artículos a cargo de Cruz, Brañes, Gaune, López Saiz, Carolina Valenzuela y Lucrecia Enríquez focalizan en los códigos discursivos y textuales; mas la consideración de códigos arquitectónicos y urbanos que proponen los trabajos de Garraffoni y de Sanfuentes permite al lector advertir la variedad de tramas capaces de vehiculizar el legado antiguo en esa orilla del Atlántico. El examen cifrado en los códigos se abre también al análisis de las prácticas e instituciones fundadas en el nuevo mundo. Como ejemplo, el caso de la persecución a la idolatría estudiado por Eduardo Valenzuela ilustra cómo el diseño y la implementación de esta práctica en América está influenciada por auctoritates antiguas que se remontan a la Biblia y la patrística; y a su turno la fundación de colegios y universidades en escenarios tan distintos como los que refieren los textos de Donoso, Del Molino, Domínguez, Vargas Valencia también dan cuenta de la profunda influencia de la tradición clásica en la implementación y labor de instituciones fundantes en esas sociedades nuevas. Códigos, prácticas e instituciones se ponen en juego en algunos de los artículos como piezas clave en la movilización de facciones, de la lucha política y de la competencia por proyectos de orden. En este punto, las contribuciones bien logradas de Gauna, muy especialmente de Huidobro, Del Molino, Domínguez, y Lucía Enríquez no sólo muestran al lector la presencia de lo clásico en América sino que exploran los usos que en esas sociedades los mantienen vigentes.

A lo largo de las páginas, por lo menos cinco conceptos que no son recogidos en la introducción intentan de maneras diferentes dar cuenta de la complejidad del vínculo entre las sociedades latinoamericanas y la herencia clásica: el de mestizaje (Vargas), el de transmisión (Brañes), el de recepción (Huidobro, López Saiz), el de autoridad (Brañes) y el de tradición (Domínguez, López Saiz, Vargas). Se tratan de conceptos que hacen pie en diversos aspectos del problema y muchos de ellos también responden a diferentes modos historiográficos de entender la relación entre culturas. Ameritaría atención particular las formas, aplicaciones y límites de este conjunto clave de categorías para este campo disciplinar.

Considerando la heterogeneidad del público lector (especialistas en historia clásica, en historia americana, estudiantes interesados en el problema, etc.), la inserción en primer lugar del artículo de Rosa Sanz sobre la herencia romana en la conquista de América resulta una decisión feliz y acertada. Con la erudición potente que la autora acostumbra, en breves páginas traza un esbozo de la relación política, religiosa e intelectual entre América y Europa presente desde la conquista. El artículo predispone al lector a advertir la complejidad del vínculo, que no solo es de forma sino que moviliza esquemas de percepción, modalidades de fuerza y técnicas de poder que descansan en último grado no solo en la violencia sino en el despliegue de la escritura. 
Dos aspectos a considerar se desprenden de la lectura global del texto. En primer lugar, el título del libro anuncia una relación entre América Latina y lo clásico, pero -y como no podría ser de otra forma- el bagaje clásico está mediado por la acción del cristianismo y la iglesia. Esto está problematizado en la contribución de Sanz y en otros artículos como en el de Lucia Enríquez, pero una vez más no figura en la agenda de cuestiones trabajadas por la introducción ni, de modo sorprendente, en el artículo de Eduardo Valenzuela que se expide sobre el bagaje bíblico y el De correctione rusticorum. En todo caso, debería especificarse qué se entiende por «lo clásico» en esta parcela, porque resulta de impacto fundamental para la inteligencia del objeto.

En segundo lugar, el orden de publicación de los artículos. Por el tema que propone, resulta difícil en una compilación de estas características atenerse a un criterio único como podría ser el cronológico o el agrupamiento por escenarios territoriales, y necesariamente lo más conveniente es combinar un aspecto y otro. El índice predispone al lector a encontrar un criterio territorial que intercala de forma subordinada un orden cronológico (primero se trata el problema en Chile desde el siglo XVI al XIX, luego en Nueva Granada durante el siglo XVIII, acto seguido en Argentina en el siglo XIX, Brasil en el siglo XX). Entre el artículo de Garrafoni y el de López Saiz -versados ambos en Brasil-, el orden cronológico se invierte dando primer lugar a la contribución de Garrafoni que trabaja sobre el siglo XX y colocando en segundo al de López Saiz centrado en la segunda mitad del siglo XIX. Las siguientes monografías de Vargas y de Valenzuela focalizan en el escenario mejicano, siendo la primera un tratamiento general y de amplio espectro cronológico, y la segunda más particular referida a la segunda mitad del siglo XVI: en tal caso el orden resulta nuevamente inteligible. La previsión vuelve a suspenderse en el caso del artículo siguiente, en el cual Enríquez trabaja sobre las galerías de los héroes chilenos. El libro con criterio se cierra con la contribución de Sanfuentes sobre la Villa Getty. Un orden de edición diferente permitiría al lector una optimización y cruzamiento más productivo de los textos, por ejemplo encontrar de forma más directa los muchos puntos de contacto entre los textos de Enríquez y Cruz, por nombrar un ejemplo; o entre los de Domínguez y Vargas, por citar otro. Tampoco el índice onomástico resulta de mucha ayuda en la tarea. Estos aspectos contribuirían a potenciar la lectura de un material muy interesante y muy pertinente para el campo. La llegada de América Latina y lo clásico. Lo clásico y América latina se celebra como una buena contribución a un objeto de estudio que, como señala uno de los autores, no recibe la atención que merece. 